\title{
Open access: academic publishing and its implications for knowledge equity in Kenya
}

\author{
Duncan Mwangangi Matheka $a^{1,2^{*}}$, Joseph Nderitu ${ }^{2,3}$, Daniel Mutonga ${ }^{1}$, Mary Iwaret Otiti ${ }^{3}$, Karen Siegel ${ }^{4}$ \\ and Alessandro Rhyll Demaio $2,5,6$
}

\begin{abstract}
Traditional, subscription-based scientific publishing has its limitations: often, articles are inaccessible to the majority of researchers in low- and middle-income countries (LMICs), where journal subscriptions or one-time access fees are cost-prohibitive. Open access (OA) publishing, in which journals provide online access to articles free of charge, breaks this barrier and allows unrestricted access to scientific and scholarly information to researchers all over the globe. At the same time, one major limitation to $\mathrm{OA}$ is a high publishing cost that is placed on authors. Following recent developments to OA publishing policies in the UK and even LMICs, this article highlights the current status and future challenges of OA in Africa. We place particular emphasis on Kenya, where multidisciplinary efforts to improve access have been established. We note that these efforts in Kenya can be further strengthened and potentially replicated in other African countries, with the goal of elevating the visibility of African research and improving access for African researchers to global research, and, ultimately, bring social and economic benefits to the region. We (1) offer recommendations for overcoming the challenges of implementing OA in Africa and (2) call for urgent action by African governments to follow the suit of high-income countries like the UK and Australia, mandating OA for publicly-funded research in their region and supporting future research into how OA might bring social and economic benefits to Africa.
\end{abstract}

Keywords: Traditional publishing, Open access, Kenya, Low- and middle-income countries, Repositories, HINARI, Policy, Libraries, Universities, Open access week

\section{Introduction}

Traditionally, scientific discoveries are shared primarily through subscription-based journals and 'fee-to-access' publications. This makes access to such scholarly literature inequitable, since access to science is based on the user's ability to pay [1]. Research findings locked behind these "pay-walls" are not disseminated as widely as possible, leading to restricted readership and thus diminishing their overall impact [2-4]. Open Access (OA) publishing attempts to address this dilemma $[2,5,6]$.

$\mathrm{OA}$ is the free, immediate, online availability of peerreviewed research articles with full re-use rights $[7,8]$. $\mathrm{OA}$ is more equitable than traditional scientific publishing and allows anyone with an internet connection, regardless

\footnotetext{
* Correspondence: dunmatheka@gmail.com

'Department of Medical Physiology, School of Medicine, University of Nairobi, PO Box 30197-00100, Nairobi, Kenya

${ }^{2}$ Young Professionals Chronic Disease Network, Boston, USA

Full list of author information is available at the end of the article
}

of where they are in the world, to access, read, and build upon the most up-to-date scientific literature $[7,8]$. It has the potential to accelerate additional discoveries, knowledge sharing and improve education [9]. Despite a number of challenges (including a frequently high publishing cost that is placed on the authors, not the readers), many scientists and researchers around the world see the value of $\mathrm{OA}$ and are working to increase its use and to reform the traditional publishing processes (the status-quo) [10,11].

OA forms also known as the roads or routes to OA include: (1) OA journals (the "Gold" road to OA), and (2) self-archiving in OA repositories (the "Green" road to OA) $[5,12,13]$. OA journals (the Gold road) do not charge users. They are peer-reviewed and published research papers, free of any access charge and with maximum opportunities for re-use. Instead, they look to other sources to fund peer-review and publication costs, including charging article processing charges (APCs) to the authors 
$[5,14]$. The green route includes self-archiving in OA repositories. In self-archiving, researchers simply deposit their refereed journal articles in open electronic archives which conform to Open Archives Initiative standards. OA repositories (Green) are online databases providing free access to the full text of research papers and other types of material. OA repositories generally host articles peerreviewed elsewhere. OA repositories can include preprints and postprints of journal articles, theses and dissertations, course materials, departmental databases, data files, audio and video files, institutional records, or digitized special collections from the library $[5,8,12,13]$. Self-archiving sustains OA repositories and this strategy helps researchers to avail their work to others faster by bypassing the rigors of journal publishing.

$\mathrm{OA}$ is becoming increasingly encouraged, even mandated, in some high-income countries (HICs). For example, the European Union (EU) runs a project to encourage all EU-funded research to place results in an OA repository and publish in OA journals [15]. At the same time, the Wellcome Trust and some countries, including the United Kingdom's (UK's) Research Council [14,16], Denmark and Australia [17], are either planning or implementing OA policies whereby the publication of publicly funded research in OA journals will be mandatory. These have been beneficial, with $\mathrm{OA}$ articles being cited earlier and more often than non-OA articles [6,13-17]. This demonstrates potential for OA to accelerate and improve scientific advancement, research visibility, knowledge dissemination, and translation of knowledge from research into practice.

These developments in HICs have the potential to impact African researchers both positively and negatively. On the one hand, scientific researchers in the African region may soon be able to access more research articles than they were previously able to. On the other hand, these same individuals may not be able to publish in gold OA journals due to the high publishing cost and the fact that most African governments, including Kenya, have no explicit policies mandating OA publishing akin to the one in UK [1,14-17].

\section{Overview of access to research publications in Africa}

There are currently two key challenges to equitable access to scientific research publications in Africa. The first is the lack of access to subscription-based scientific journals. Traditionally, when scientific breakthroughs relevant to Africa are made, they are published in non-OA journals whose prohibitive subscription (or access) costs are often in the order of US\$30 per paper (The price per article for Elsevier journals on ScienceDirect is US\$31.50 as of November 11, 2013) [18], which is unaffordable for most researchers in LMICs [19].

The high subscription cost inhibits the exposure of African research scientists to these discoveries and their ability to either use the most up-to-date research knowledge to strengthen their research or to build upon said research [19-21]. This can lead to additional adverse consequences on education and research in Africa, which leads to a perpetuated cycle of restricted knowledge. African research scientists might lack access to their fellow researchers' work, and students may lack access to the work of their senior colleagues and researchers around the world. Researchers and students therefore lack capacity to practice evidence-based science confounding further to the challenges in implementing research projects and translating research findings into marketable products $[13,22]$.

To curb the costs of journal subscriptions, the World Health Organization (WHO), through Health Inter Network Access to Research Initiative (HINARI), facilitates free access to over 3,000 journals in most LMICs [23]. Through HINARI, publishers give institutions in LMICs free access to electronic editions of journals. This is through a WHO-funded platform that can be accessed via a username and a password - which are available among researchers in LMICs [23-25]. Moreover, programs such as authorAID workshops exist, which encourage research and facilitate the process for authors [26].

OA journals also address these access issues, and a number of OA research journals have been launched in Africa, with South Africa being on the lead [1,27-31]. Scholarly Communication in Africa Program (SCAP) also aims to increase the visibility of African research via research journals as well as other ways of disseminating such work [31].

However, these OA journals raise the second key challenge to equitable access to research and knowledge sharing in Africa: to offset the fact that OA journals have no subscription costs, they shift this burden to authors, charging high publishing fees ranging from US\$1000 to US $\$ 2500$ per publication [1,21]. This precludes African research scientists from being able to publish their findings in these OA journals. To address this, some OA journals currently offer APC waivers to researchers who cannot cover OA journals' publishing costs. Public Library of Science (PLOS) [32] and BioMed Central (BMC) [10] are both examples of publishers with automatic waivers for researchers based in LMICs, as classified by the World Bank [1]. Researchers in a country on the waiver list would not face any financial barrier when publishing in these OA journals [1].

\section{Overview of $O A$ initiatives in Kenya}

Although OA is still burgeoning in Africa, several established initiatives exist, such as the following, in Kenya.

\section{Role of libraries}

Through the Kenya Library and Information Services Consortium (KLISC), libraries in Kenya are at the fore- 
front advocating for OA journal publishing and policies [33,34]. KLISC was formed in 2004, when Kenyan public universities came together with the help of International Network for the Availability of Scientific Publications (INASP) [35]. Its current membership includes Kenyan private universities, public libraries, museums and research institutions with the aim of ensuring access to electronic resources, including OA materials [34].

Kenyan libraries are also members of the Programme for Enhancement of Research Information (PERii) since 2001. PERii promotes OA through compiling a list of OA resources, promoting $\mathrm{OA}$ repositories and supporting publishing - for example, Africa Journals Online (AJOL) and authorAID Project [26,30]. The Electronic Information for Libraries (EIFL), has also catapulted the drive for OA in Kenya [33,34,36].

The librarians of the University of Nairobi have significantly contributed in ensuring the adoption of an OA policy by the University. This was accomplished through a series of trainings to the dons of the university on the role of $\mathrm{OA}$ in advancement of research, and associated benefits for the institution [37].

\section{Open access research journals}

There are a number of OA research journals that have been launched in Kenya, mainly run by Kenyan institutions such as Kenya Medical Research Institute, University of Nairobi, among others $[28,29]$. These are often free to the researcher as well as the reader, with the publishing costs being incurred by the hosting institutions. However, there are challenges faced in the quality of such journals, as well as their peer review process, relative impact factors and sustainability.

\section{Universities and other institutions}

Various institutions in Kenya have adopted OA policies making research work carried out by these institutions openly accessible. They run e-repositories where research conducted by their students and faculty is deposited [37]. Some universities and institutions are already running OA journals too $[28,29]$.

OA policies have already been adopted by several Kenyan institutions including Strathmore University, Multimedia University, University of Nairobi, Kenyatta University, Jomo Kenyatta University of Agriculture and Technology, African Population and Health Research Centre, among others [33,34].

Moreover, most Kenyan institutions now ensure access to wireless internet connection throughout their facilities. This is an important step in creating a framework to take full advantage of OA and to create and sustain OA repositories.

\section{Students and open access week}

Every year, there is a global OA Week [38] - an event to bring attention to this rapidly emerging form of scientific publication. In Kenya, the University of Nairobi and Jomo Kenyatta University of Agriculture and Technology libraries and students have over the years used this week to create more OA awareness in their institutions [35,39].

Through the Medical Students' Association of Kenya (MSAKE), a member of the International Federation of Medical Students' Association, this week has been marked by students in all public medical schools in Kenya (University of Nairobi, Moi University, Kenyatta University and Egerton University) in 2012 [1,35]. MSAKE also runs a blog and social media websites all year round as a tool for advocacy and creating OA awareness [40].

\section{Kenyan government}

Like most African governments, the Kenyan government has no explicit policies mandating OA publishing akin to those in the UK and Australia [14-17]. However, it has made steps in funding local research through its National Commission for Science, Technology and Innovation. Through this commission, grants have been administered to support scientific research and innovations for national development, targeting priority areas in relation to the development agenda of the government. Since inception of this program in 2008/2009, it has stimulated renewed interest among researchers and innovators in various institutions across the country [41].

\section{Recommendations for open access in Africa}

Besides the advances made on OA in Kenya, a number of constraints to equitable access to scientific research publications still exist. Like other LMICs, Kenya lacks access to expensive subscription-based scientific journals and OA policies, and researchers are burdened by high publishing fees. Therefore, it is prudent to strengthen the efforts in Kenya, and potentially replicate in other African nations.

OA implementation requires multidisciplinary input and therefore needs various stakeholders (governments, researchers, institutions, journals, libraries, civil society, non-governmental organizations (NGOs), policymakers, Information and communications technology (ICT), students) to work collaboratively to solve these challenges.

\section{Government}

An important step for African governments would be to implement policies to ensure that research findings are shared widely, through public funding for OA publishing costs. Additionally, there should be legislative measures mandating OA publishing for all research pioneered by African governments or that which is publicly funded. The EU launched its bid to have all EU-funded work to 
be made available to researchers without discrimination [14-17]. It is necessary for African governments to follow this example since this will be an important catalyst to scientific innovation in the region. Government funding for medical research is either lacking or minimal in African countries. A big step would be for the African governments to establish or increase funding for medical research which would help cover the publishing cost.

\section{Researchers}

African researchers should support OA by publishing their research in OA journals, and/or deposit their peer-reviewed manuscripts in OA repositories. This will ensure equity and a benefit to the people who funded the work, as well as to fellow researchers.

\section{Non-government sector}

Institutions, libraries, civil society and NGO policy makers should also be at the forefront in embracing OA. They need to encourage more research and publishing. Moreover, OA policies should be adopted by institutions in African countries, as done by institutions in HICs - Harvard University, Stanford University, National Institutes of Health, Wellcome Trust, Canadian Cancer Society, Autism Speaks, and Canadian Institutes of Health Research [16,42-44].

\section{Advocacy}

Advocacy for OA is crucial towards securing the support by universities, governments, research funders, charitable funders and other organizations. This should also be aimed at more journals giving waivers to LMICs or those who cannot afford APCs. Like in Kenya, students also have a role to play in advocacy for OA and even for necessary infrastructure and policies.

\section{Journals}

There is a role to encourage establishment of more OA journals in Africa, as well as committing more resources to ensure better quality, peer review and sustainability of these journals. For the traditional journals, there is a role for their retrospective digitalization and integration with existing ICT. Through this, the 'traditional' academic journals can be incentivized to change their business models and make scientific knowledge open to all.

\section{Research funding bodies}

Lastly, there is need to find a solution to the dilemma of funding for publications from LMICs. Can LMIC governments fund publishing costs? Can researchers and LMICs liaise with more publishers to waiver APCs for researchers from LMICs? Can there be constant funders to support publication fees for researchers from LMIC (just like the WHO-pioneered HINARI for access to journals)? or Can publishing fees be abolished?

\section{Conclusions}

Open Access is crucial for the process of informing the scientific community on research outcomes since it ensures quicker, more direct access to research results and reduces inequities in scientific access. With Africa currently facing serious challenges in research and publishing, multidisciplinary support mandating OA publication is urgently needed - a move that is likely to bring social and economic benefits in Africa and elevate the visibility of African research around the world. We note that the multidisciplinary efforts in Kenya can be strengthened and potentially replicated in other African countries. We recommend that the African governments mandate OA for publicly funded research in their region akin to UK and Australia, as well as support research into the economic and social benefits of OA for the African region.

\section{Abbreviations}

APCs: Article processing charges; EU: European union; HINARI: Health inter network access to research initiative; HICs: High-income countries; KLISC: Kenya library and information services consortium; LMICs: Low- and middle-income countries; NGOs: Non-governmental organizations; OA: Open access; UK: United Kingdom; WHO: World Health Organization.

\section{Competing interests}

The authors declare that they have no competing interests.

\section{Author's contributions}

DMM conceived and wrote the first draft of the manuscript. DM MO KS and $\mathrm{AD}$ contributed significantly to the writing and review of the manuscript. All authors read and approved the final manuscript.

\section{Acknowledgements}

The authors thank Nick Shockey for his assistance in reviewing the article.

\section{Author details}

${ }^{1}$ Department of Medical Physiology, School of Medicine, University of Nairobi, PO Box 30197-00100, Nairobi, Kenya. ${ }^{2}$ Young Professionals Chronic Disease Network, Boston, USA. ${ }^{3}$ Department of Human Anatomy, School of Medicine, University of Nairobi, Nairobi, Kenya. ${ }^{4}$ Nutrition and Health Sciences, Graduate Division of Biological and Biomedical Sciences, Laney Graduate School and Department of Global Health, Rollins School of Public Health, Emory University, Atlanta, GA, USA. ${ }^{5}$ Department of International Health, Immunology and Microbiology, Copenhagen School of Global Health, University of Copenhagen, Copenhagen, Denmark. ${ }^{6}$ Harvard Global Equity Initiative, Department of Global Health and Social Medicine, Harvard Medical School, Boston, USA.

Received: 10 December 2013 Accepted: 4 April 2014

Published: 9 April 2014

\section{References}

1. Sarah G: A week of open access conferencing: Part 1. http://openuct.uct.ac.za/ blog/week-open-access-conferencing-part-1. Accessed 22 November 2013.

2. Björk B-C, Welling P, Laakso M, Majlender P, Hedlund T, Gudnason G: Open Access to the Scientific Journal Literature: Situation 2009. PLoS One 2010, 5(6):e11273. doi:10.1371/journal.pone.0011273.

3. Albert KM: Open access: Implications For Scholarly Publishing And Medical Libraries. J Med Libr Assoc 2006, 94(3):253-262.

4. Burton A: Sharing science: Enabling Global Access to the Scientific Literature. Environ Health Persp 2011, 119(12):520-523.

5. Harnad S, Brody T: Vallie'res F, Carr L, Hitchcock S, Gingras Y, Oppenheim C, Stamerjohanns H, Hilf ER: The Access/Impact Problem and the Green and Gold Roads to Open Access. Ser Rev 2004, 30:310-314.

6. Norris M, Oppenheim C, Rowland F: The Citation Advantage of Open-Access Articles. J Am Soc Inf Sci Tec 2008, 59:1963-1972. doi:10.1002/asi.20898. 
7. Velterop J: Should scholarly societies embrace open access (or is it the kiss of death)? Learn Publish 2003, 16:167-169.

8. Suber P: Open Access Overview: Focusing on Open Access to Peer-Reviewed Research Articles and Their Preprints. http:/legacy.earlham.edu/ peters/fos/ overview.htm. Accessed 22 November 2013.

9. Swan A: Open Access and The Progress of Science. Am Sci 2007, 95:198-200.

10. Biomed Central (BMC). http://www.biomedcentral.com/about/advocacy12. Accessed 22 November 2013

11. Houghton J, Rasmussen B, Sheehan P, Oppenheim C, Morris A, Creaser C, Greenwood H, Summers M, Gourlay A: Economic implications of alternative scholarly publishing models: Exploring the costs and benefits. Project Report 2009, http.//www.jisc.ac.uk/publications/reports/2009/economicpublishing modelsfinalreport.aspx. Accessed 22 November 2013.

12. Scholarly Publishing and Academic Resources Coalition (SPARC). http://www.sparc.arl.org/openaccess/. Accessed 22 November 2013.

13. Right to Research Coalition: Why Open Access? http://www. righttoresearch.org/learn/whyOA/index.shtml. Accessed 22 November 2013.

14. RCUK Proposed Policy on Access to Research Outputs: http://www. openscholarship.org/upload/docs/application/pdf/2012-03/ rcuk_proposed_policy_on_access_to_research_outputs.pdf. Accessed 29 May 2014.

15. Sample I: Free access to British scientific research within two years. The Guardian 2012. http://www.guardian.co.uk/science/2012/jul/15/free-access-british-scientificresearch. Accessed 22 November 2013.

16. Wellcome Trust: Open access policy: Position statement in support of open and unrestricted access to published research. http:/www.wellcome. ac.uk/About-us/Policy/Spotlight-issues/Open-access/Policy/index.htm Accessed 22 November 2013.

17. Hood L: ARC poised to join open-access movement. http://www. researchresearch.com/index.php?articleld=1251042\&option=com news\&template=rr_2col\&view=article. Accessed 22 November 2013.

18. Science direct. http://www.sciencedirect.com/science/journal/14635003. Accessed 22 November 2013.

19. Dulle FW, Minishi-Majanja MK: Researchers' Perspectives on Open Access Scholarly Communication In Tanzanian Public Universities. S Afr J Inform Manag 2009, 11(4). doi:10.4102/sajim.v11i4.413.

20. Ondari-Okemwa E: Scholarly publishing in sub-saharan Africa in the twenty-first century, challenges and opportunities. First Monday 2007, 12(10). http://pear.accc.uic.edu/ojs/index.php/fm/article/view/1966/1842. Accessed 22 November 2013

21. Raju R, Smith I, Gibson H: Opening access to African scholarly content: Stellenbosch University's AOARI platforms. Insights 2013, 26(1):44-50. doi:10.1629/2048-7754.26.1.44.

22. Godlee F, Pakenham-walsh N, Ncayiyana D, Cohen B, Packer A: Can We Achieve Health Information for All by 2015? Public Health 2004. http://image. thelancet.com/extras/04art6112web.pdf. Accessed 22 November 2013.

23. Health Inter Network Access to Research Initiative (HINARI). http://www. who.int/hinari/en/. Accessed 22 November 2013.

24. Katikireddi SV: HINARI: bridging the global information divide. BMJ 2004, 328:1190-1193.

25. Aronson B: Improving Online Access to Medical Information for Low Income Countries. NEJM 2004, 350(10):966-968.

26. Walker J: The AuthorAID Project at INASP: Building On Holistic Approach To Research Communication. Serials 2009, 22(3):220-223.

27. Pan African Medical Journal. http://www.panafrican-med-journal.com/. Accessed 22 November 2013.

28. University of Nairobi Academic Journals. http://journals.uonbi.ac.ke/. Accessed 22 November 2013

29. The African Journal of Health Sciences. http://www.ajhsjournal.or.ke/. Accessed 22 November 2013

30. Rosenberg D: African Journals OnLine (AJOL): An Internal Evaluation 2000-2002. INASP 2003. http://www.inasp.info. Accessed 22 November 2013.

31. Scholarly Communication in Africa Program. http://www.scaprogramme. org.za/blog/. Accessed 22 November 2013.

32. PLOS: The Case for Open Access. http://www.plos.org/about/open-access/. Accessed 22 November 2013

33. Kenya Library and Information Services Consortium (KLISC). http://www.eifl.net/kenya-libraries-and-information-services-consortiu. Accessed 22 November 2013.

34. Otando RM: Building Institutional Repositories in KLISC Member Institutions in Kenya: Current Status and Emerging challenges. UoN repository 2011. http://erepository.uonbi.ac.ke/handle/123456789/25736. Accessed 22 November 2013.

35. International Network for the Availability of Scientific Publications (INASP) http://www.inasp.info/kenya. Accessed 22 November 2013.

36. Electronic Information for Libraries (EIFL). http://www.eifl.net/news/ university-nairobi-open-access-policy. Accessed 22 November 2013.

37. Kabugu AN: Enhancing The Visibility And Accessibility Of Research: Demysifying and Promoting Open Access at the University of Nairobi. INASP 2013. http://www.inasp.info/uploads/filer_public/2013/04/22/enhancing_the_ visibility_and_accessibility_of_research.pdf. Accessed 22 November 2013.

38. Open Access Week. http://www.openaccessweek.org. Accessed 22 November 2013.

39. University of Nairobi Library Open Access Week. http://www.uonbi.ac.ke/ node/4791. Accessed 22 November 2013.

40. MSAKE Facebook Open Access Initiative. http://www.facebook.com/ pages/Open-Access-Initiative MSAKE/415282921870884?fref=ts. Accessed 22 November 2013.

41. Kenya National Commission for Science, Technology and Innovation. http://www.nacosti.go.ke/. Accessed 22 November 2013.

42. Stanford University. http://ed.stanford.edu/suse/faculty/openaccess.html. Accessed 22 November 2013

43. National Institutes of Health. http://publicaccess.nih.gov/policy.htm. Accessed 22 November 2013.

44. Autism Speaks. http://www.autismspeaks.org/science/overview/policies/ policy_on_public_access_to_research.php. Accessed 22 November 2013.

\section{doi:10.1186/1744-8603-10-26}

Cite this article as: Matheka et al:: Open access: academic publishing and its implications for knowledge equity in Kenya. Globalization and Health 2014 10:26.

\section{Submit your next manuscript to BioMed Central and take full advantage of:}

- Convenient online submission

- Thorough peer review

- No space constraints or color figure charges

- Immediate publication on acceptance

- Inclusion in PubMed, CAS, Scopus and Google Scholar

- Research which is freely available for redistribution 